\title{
Phytochemical Characteristics of Coffee Bean Treated by Coating of Ginseng Extract
}

\author{
Sang Yoon Choi ${ }^{1}$, Hee-Do Hong ${ }^{1}$, Hye-Min Bae ${ }^{1}$, Changsun Choi ${ }^{2}$, and Kyung-Tack Kim ${ }^{1 *}$ \\ ${ }^{1}$ Korea Food Research Institute, Seongnam 463-746, Korea \\ ${ }^{2}$ Department of Food and Nutrition, School of Food Science and Technology, Chung-Ang University, Anseong 456-756, Korea
}

The principal objective of this study was to assess the instrumental and sensory characteristics of ginseng coffee with different ratios of the ingredients: type of coffee bean (Colombia, Brazil, and Indonesia), type of ginseng extract (white ginseng, red ginseng, and America ginseng) and concentration of ginseng extract (3, 6, and $9 \mathrm{w} / \mathrm{v} \%)$. The sensory optimal condition of white ginseng coffee, red ginseng coffee and America ginseng coffee were as follows: $3 \%$ Indonesian coffee bean coated with $3 \%$ white ginseng extract, Colombian coffee bean coated with $6 \%$ red ginseng extract and Colombian coffee bean coated with $3 \%$ American ginseng extract, respectively. In particular, the Colombian coffee bean coated with $6 \%$ red ginseng extract had significantly higher scores than other samples in terms of flavor, taste, and overall preference. Additionally, the contents of total ginsenoside and total sugar and total phenolic compounds were also highest in the Colombian coffee bean coated with $6 \%$ red ginseng extract.

Keywords: Panax ginseng, Ginseng coffee, Red ginseng, Coffee bean, Ginsenoside, Sensory evaluation

\section{INTRODUCTION}

Ginseng (Panax ginseng Meyer), a member of the Araliaceae family, is a perennial plant, the roots of which have been employed as an herbal medicine. Including $P$. ginseng, there are 13 Panax species known, including $P$. quinquefolius, $P$. notoginseng, P. japonicum, P. trifolium, and $P$. vietnamensis, among others. The roots of the ginseng can be classified into white ginseng (dried roots) and red ginseng (dried roots after steaming using water vapor, etc.) based on the manufacturing process employed [1].

As interest in health issues steadily grows, demand for ginseng products to prevent and treat illness is also increasing [2]. Many aspects of ginseng's pharmacological efficacy and functionality have been elucidated thus far, via a number of studies. As ginseng also goes well with many foods, its value as a functional food has appreciated. The results are currently being applied to a variety of

(cC) This is an Open Access article distributed under the terms of the Creative Commons Attribution Non-Commercial License (http://creativecommons.org/licenses/by-nc/3.0/) which permits unrestricted non-commercial use, distribution, and reproduction in any medium, provided the original work is properly cited. products, including drinks, rice cakes, cakes, jelly, salad dressing [3-7], and many others.

Coffee is currently the most widely consumed drink in the world, with daily consumption standing at approximately to 2.5 billion cups [8]. Moreover, a broad variety of coffee products, to which other healthy ingredients such as popular herbs or green tea are added to strengthen its effectiveness, has appeared on the market. Ginseng coffee products have been manufactured and sold in Korea, the Philippines, India, Malaysia, Japan, and China, although the level of manufacturing technology is still as basic as the simple mixing of ginseng powder with coffee extract powder. Considering the current status of this manufacturing technology and the market trend toward more sophisticated products, it is believed that ginseng coffee bean products will generate a new opportunity

Received 06 May. 2011, Revised 30 Aug. 2011, Accepted 30 Aug. 2011

\footnotetext{
*Corresponding author

E-mail: tack@kfri.re.kr

Tel: +82-31-780-9096, Fax: +82-31-709-9876
} 
Table 1. Concentration of coating extracts

\begin{tabular}{|c|c|c|}
\hline Samples & Coffee beans & Ginseng extracts (w/v \%) \\
\hline \multirow[t]{3}{*}{ CWGC bean } & Colombia & White ginseng extract (3) \\
\hline & Colombia & White ginseng extract (6) \\
\hline & Colombia & White ginseng extract (9) \\
\hline \multirow[t]{3}{*}{ IWGC bean } & Indonesia & White ginseng extract (3) \\
\hline & Indonesia & White ginseng extract (6) \\
\hline & Indonesia & White ginseng extract (9) \\
\hline \multirow[t]{3}{*}{ BWGC bean } & Brazil & White ginseng extract (3) \\
\hline & Brazil & White ginseng extract (6) \\
\hline & Brazil & White ginseng extract (9) \\
\hline \multirow[t]{3}{*}{ CRGC bean } & Colombia & Red ginseng extract (3) \\
\hline & Colombia & Red ginseng extract (6) \\
\hline & Colombia & Red ginseng extract (9) \\
\hline \multirow[t]{3}{*}{ IRGC bean } & Indonesia & Red ginseng extract (3) \\
\hline & Indonesia & Red ginseng extract (6) \\
\hline & Indonesia & Red ginseng extract (9) \\
\hline \multirow[t]{3}{*}{ BRGC bean } & Brazil & Red ginseng extract (3) \\
\hline & Brazil & Red ginseng extract (6) \\
\hline & Brazil & Red ginseng extract (9) \\
\hline \multirow[t]{3}{*}{ CAGC bean } & Colombia & America ginseng extract (3) \\
\hline & Colombia & America ginseng extract (6) \\
\hline & Colombia & America ginseng extract (9) \\
\hline \multirow[t]{3}{*}{ IAGC bean } & Indonesia & America ginseng extract (3) \\
\hline & Indonesia & America ginseng extract (6) \\
\hline & Indonesia & America ginseng extract (9) \\
\hline \multirow[t]{3}{*}{ BAGC bean } & Brazil & America ginseng extract (3) \\
\hline & Brazil & America ginseng extract (6) \\
\hline & Brazil & America ginseng extract (9) \\
\hline
\end{tabular}

CWGC, white ginseng Colombian coffee; IWGC, white ginseng Indonesian coffee; BWGC, white ginseng Brazilian coffee; CRGC, red ginseng Colombian coffee; IRGC, red ginseg Indonesian coffee; $B R G C$, red ginseng Brazilian coffee; CAGC, American ginseng Colombian coffee; IAGC, American ginseng Indonesian coffee; BAGC, American ginseng Brazilian coffee.

in the global ginseng market by transferring the active ingredients of ginseng to the coffee bean. Therefore, in this study, we evaluated the quality characteristics of ginseng coffee produced via the processing of various types of coffee bean with a micro-coating solution containing ginseng extract derived from a variety of ginseng types combined with hydroxypropyl methyl cellulose (HPMC).

\section{MATERIALS AND METHODS}

\section{Materials}

Unprocessed coffee beans including a Columbian coffee (Supremo), a Brazilian coffee (Natural), and an
Indonesian coffee (Mandheling) were purchased from Coffee Nouri Co. (Seoul, Korea). White ginseng extract was purchased from Guan Industry Co. (Seoul, Korea); red ginseng extract was purchased from Korea Ginseng Corporation (Daejeon, Korea); and American ginseng extract powder was purchased from Hongjiu Biotech (Jilin, China). HPMC was purchased from Samsung Chemical Co. (Seoul, Korea).

\section{Preparation of ginseng coffee bean}

Each ginseng coating solution was prepared to $9^{\circ}$ Brix by mixing each ginseng extract with $2.5 \mathrm{w} /$ v \% HPMC solution. Ginseng coffee beans were prepared from three different kinds of coffee beans (Columbian coffee, Brazilian coffee, and Indonesian coffee) roasted at $250^{\circ} \mathrm{C}$ for $15 \mathrm{~min}$ and coated with a ginseng coating solution, as shown in Table 1.

\section{Sensory evaluation}

Ginseng coffee beans were extracted using distilled water through a coffee machine (BCO 120T; DeLonghi, Bedford Heights, $\mathrm{OH}, \mathrm{USA}$ ) at $100^{\circ} \mathrm{C}$ for $5 \mathrm{~min}$. The coffee samples were maintained at $65^{\circ} \mathrm{C}$ and provided to the panelists in $50 \mathrm{~mL}$-sized amounts. Sensory evaluations were performed by 15 trained panelists to test different coffee beans blended with different kinds and quantities of ginseng extracts. Forty trained panelists participated in the sensory evaluation for the 3 ginseng coffees (white, red, and American ginseng coffee) made using the ultimately selected formula. The palatability test was carried out by scoring the color, flavor, taste, and overall palatability of the coffee samples, with a score of 9 indicating the highest level of palatability. The same scoring system was used for the intensity test, in which the coffee flavor, coffee taste, ginseng flavor, and ginseng taste of the different samples were evaluated.

\section{Measurement of chromaticity and $\mathrm{pH}$}

The chromaticity of the coffee bean surfaces was assessed by a spectrocolorimeter (Color QUEST; Hunter Lab Co., Reston, VA, USA), calibrated with a standard white board (lightness $[\mathrm{L}]=92.68$, redness $[\mathrm{a}]=0.81$, yellowness $[\mathrm{b}]=0.86)$. Chromaticity was calculated as mean values using the formula $\Delta E=\sqrt{ }(\Delta L)^{2}+(\Delta a)^{2}+(\Delta b)^{2}$ after measuring L, a, and b (Hunter Lab Co.) in triplicate. In terms of $\mathrm{pH}$, one gram of ground sample was added to $100 \mathrm{~mL}$ of distilled water, extracted with a stirrer, filtered through Whatman no. 2 filter paper, and measured with a $\mathrm{pH}$ meter ( $\mathrm{pH}$ meter 430; Corning Inc., Corning, NY, USA). 


\section{Determination of total sugar and acidic polysac- charide content}

Two grams of sample was added to $100 \mathrm{~mL}$ of distilled water, extracted with a reflux condenser, and filtered through Whatman no. 2 filter paper. This extract was filtered using a $0.45 \mu \mathrm{m}$ membrane filter and used for total sugar analysis. For acidic polysaccharide analysis, 20 $\mathrm{mL}$ of heated water extract was used and $80 \mathrm{~mL}$ of cold ethanol was added to precipitate the polysaccharides. Polysaccharide particles were collected via $20 \mathrm{~min}$ of centrifugation at $10,000 \mathrm{x} \mathrm{g}$ at $4^{\circ} \mathrm{C}$, and the precipitate was resuspended in distilled water and used for acidic polysaccharide content analysis. Total sugar content was quantified via the phenol-sulfuric acid method [9] using glucose as the standard, whereas acidic polysaccharide content was quantified via the carbazole-sulfuric acid method [10] using $\beta$-D-galacturonic acid as the standard.

\section{Determination of total phenolic compound con- tent}

Fifty milliliters of $80 \%$ aqueous methanol was added to $2 \mathrm{~g}$ of ground sample. Soluble components were extracted with a reflux condenser. The extract was filtered through Whatman no. 2 filter paper and condensed under vacuum, dissolved in $30 \mathrm{~mL}$ of distilled water, filtered through a $0.45 \mu \mathrm{m}$ membrane filter, and subsequently used for total phenolic compound content analysis. Total phenolic compound content was quantified via the FolinCiocalteu method [11], and chlorogenic acid was used as the standard.

\section{Determination of ginsenoside content}

Separation and quantitation of ginsenoside was carried out using a Sep-pak separation technique in accordance with Korean Industry Standard (KS) H 2153 from the Korean Standard Information Center. This method consisted of extracting $10 \mathrm{~g}$ of coffee sample with $150 \mathrm{~mL}$ of water with a stirrer. Samples were extracted twice, and the resultant extract was filtered with Whatman no. 2 filter paper. The sample remained after filtration was then washed in $100 \%$ methanol. It was then condensed under vacuum and dissolved in $30 \%$ aqueous methanol, followed by dissolution in $25 \mathrm{~mL}$ of sample extraction solution. Next, $5 \mathrm{~mL}$ of the sample was passed through a Sep-pak $\mathrm{C}_{18}$ cartridge. The filtrate was discarded, and the Sep-pak $\mathrm{C}_{18}$ cartridge was washed with $30 \%$ aqueous methanol. Five milliliters of methanol was passed through it and filtered through a $0.45 \mu \mathrm{m}$ membrane filter, to be used as samples for ginsenoside composition analyses. This stage used a $\mu$ Bondapak ${ }^{\mathrm{TM}} \mathrm{C}_{18}$ Column
(10 $\mu \mathrm{m}, 3.9 \times 300 \mathrm{~mm}$; Waters, Milford, MA, USA) and a Jasco UV detector (203 nm). A water-acetonitrile (HPLC-grade; Sigma, St. Louis, MO, USA) gradient was also employed. The acetonitrile mobile phase varied according to the following schedule: $20 \%$ (0 $\mathrm{min}$ ), 20\% (5 min), 33\% (38 min), 80\% (63 min), 80\% (75 min), 20\% (77 $\mathrm{min}$ ), and 20\% (90 $\mathrm{min}$ ). The mobile phase flow rate was set at $1.0 \mathrm{~mL} / \mathrm{min}, 20 \mu \mathrm{L}$ of sample was injected, and the sample was analyzed at $35^{\circ} \mathrm{C}$.

\section{Caffeine content}

Caffeine content was quantified using a SunFire ${ }^{\mathrm{TM}} \mathrm{C}_{18}$ Column ( $5 \mu \mathrm{m}, 4.6 \times 250 \mathrm{~mm}$, Waters $)$ and a Jasco UV detector $(280 \mathrm{~nm})$. The mobile phase was composed of $20 \%(\mathrm{v} / \mathrm{v})$ of HPLC-grade methanol, $1 \%(\mathrm{v} / \mathrm{v})$ of acetic acid, and 79\% (v/v) HPLC-grade water (HPLC-grade, Sigma). Running time was set for $30 \mathrm{~min}$ at a flow rate of $1 \mathrm{~mL} / \mathrm{min} .1 \mathrm{~g}$ of coffee bean sample was extracted with $100 \mathrm{~mL}$ of water with stirrer, and then filtered through a $0.45 \mu \mathrm{m}$ membrane filter. Sample injection volume was set at $20 \mu \mathrm{L}$. Measurements were repeated in triplicate.

\section{Statistical analysis}

The results of the sensory evaluation were analyzed using the SPSS ver. 10.0 (SPSS Inc., Chicago, IL, USA). In an effort to confirm the significance of the mean difference among the test groups, Duncan's multiple range test was applied at a significance level of $0.05(p<0.05)$.

\section{RESULTS AND DISCUSSION}

\section{Sensory characteristics of ginseng coffee samples}

The high scores in the sensory evaluation, which were conducted to assess the taste and palatability of the sample coffees, were observed in the $3 \%$ white ginseng Indonesian coffee (IWGC), 6\% red ginseng Colombian coffee (CRGC), and 3\% American ginseng Colombian coffee (CAGC). The results of the sensory evaluation for the three ginseng coffees are shown in Table 2. In the fragrance test, $6 \% \mathrm{CRGC}$ was rated as the most palatable, followed by the 3\% IWGC and 3\% CAGC samples (in order); the differences in palatability among samples were statistically significant. 6\% CRGC also scored highest on the taste and overall palatability tests, but this was not statistically significant as compared to the $3 \%$ IWGC. We noted no significant differences among the test groups in the intensity test of coffee flavor, but the $6 \%$ CRGC scored highest in coffee taste intensity. In the ginseng flavor and taste intensity test, the 3\% CAGC scored highest, followed by the 3\% IWGC and 6\% CRGC 
Choi et al. Characteristics of Ginseng Coffee

Table 2. Sensory chracteristics of ginseng coffees

\begin{tabular}{|c|c|c|c|c|c|c|c|c|}
\hline \multirow[b]{2}{*}{ Samples } & \multicolumn{4}{|c|}{ Consumer preference } & \multicolumn{4}{|c|}{ Consumer intensity } \\
\hline & Color & Flavor & Taste & Overall & Coffee flavor & Coffee taste & Ginseng flavor & Ginseng taste \\
\hline CRGC (6\%) & $6.18 \pm 1.36$ & $6.30 \pm 1.40^{\mathrm{b}}$ & $6.27 \pm 1.44^{\mathrm{b}}$ & $6.30 \pm 1.45^{\mathrm{b}}$ & $6.09 \pm 1.42$ & $6.00 \pm 1.50^{\mathrm{b}}$ & $2.91 \pm 1.63^{\mathrm{a}}$ & $3.27 \pm 1.75^{\mathrm{a}}$ \\
\hline IWGC (3\%) & $6.03 \pm 1.31$ & $5.58 \pm 1.54^{\mathrm{ab}}$ & $5.64 \pm 1.25^{\mathrm{b}}$ & $5.76 \pm 1.28^{\mathrm{b}}$ & $5.33 \pm 1.51$ & $5.27 \pm 1.74^{\mathrm{ab}}$ & $4.18 \pm 1.70^{\mathrm{b}}$ & $5.00 \pm 1.92^{\mathrm{b}}$ \\
\hline CAGC (3\%) & $5.73 \pm 1.13$ & $5.24 \pm 1.80^{\mathrm{a}}$ & $4.12 \pm 1.65^{\mathrm{a}}$ & $4.27 \pm 1.68^{\mathrm{a}}$ & $5.39 \pm 1.64$ & $4.73 \pm 1.96^{\mathrm{a}}$ & $4.94 \pm 1.94^{\mathrm{b}}$ & $6.52 \pm 1.54^{\mathrm{c}}$ \\
\hline$F$-value & $1.10^{1)}$ & $3.83^{*}$ & $19.00^{* * *}$ & $16.69^{* * *}$ & $2.51^{1)}$ & $4.44^{*}$ & $11.21^{* * *}$ & $28.48^{* * *}$ \\
\hline
\end{tabular}

Data are expressed as mean \pm SD.

CRGC, red ginseng Colombian coffee; IWGC, white ginseng Indonesian coffee; CAGC, American ginseng Colombian coffee.

${ }^{1)}$ Not significant.

Significant at $" p<0.05, " p<0.01,{ }^{* * *} p<0.001$.

Table 3. Physiochemical characteristics of ginseng coffee beans

\begin{tabular}{|c|c|c|c|c|}
\hline & $L$-value & $a$-value & $b$-value & $\mathrm{pH}$ \\
\hline Colombia bean (control) & $22.10 \pm 1.50$ & $5.02 \pm 0.22$ & $5.75 \pm 1.05$ & $5.56 \pm 0.01$ \\
\hline CRGC bean $(6 \%)$ & $23.21 \pm 0.99$ & $5.49 \pm 0.41$ & $6.23 \pm 0.90$ & $5.36 \pm 0.02$ \\
\hline CAGC bean $(3 \%)$ & $23.76 \pm 0.55$ & $4.76 \pm 0.58$ & $5.25 \pm 0.76$ & $5.48 \pm 0.01$ \\
\hline Indonesia bean (control) & $23.46 \pm 1.49$ & $5.12 \pm 0.68$ & $6.30 \pm 1.26$ & $5.43 \pm 0.02$ \\
\hline IWGC bean $(3 \%)$ & $23.59 \pm 1.49$ & $5.41 \pm 0.68$ & $6.37 \pm 0.94$ & $5.40 \pm 0.02$ \\
\hline
\end{tabular}

Data are expressed as mean \pm SD.

CRGC, red ginseng Colombian coffee; CAGC, American ginseng Colombian coffee; IWGC, white ginseng Indonesian coffee.

samples (in order). As shown in the results, the lower ginseng flavor and taste intensity of the red ginseng coffee compared to the other ginseng coffees coated with a smaller amount of ginseng extract indicates that red ginseng extract has milder ginseng taste and flavor than the other two ginseng extracts.

\section{Chromaticity and pH of ginseng coffee beans}

The chromaticity and $\mathrm{pH}$ of the ginseng coffee beans are shown in Table 3 . The $L$-value, indicating luminosity, of the ginseng coffee beans evidenced an increase relative to the control groups, i.e., the original coffee beans. The redness scores, which are indicated as $a$-values, were as follows: 5.02 for the Columbian coffee beans; 5.49 for the $6 \% \mathrm{CRGC}$ bean; 4.76 for the $3 \% \mathrm{CAGC}$ bean; 5.12 for the Indonesian coffee beans, and 5.41 for the $3 \%$ IWGC bean. The yellowness scores, which are indicated as b-values, were as follows: 5.75 for the Columbian coffee beans; 6.23 for the $6 \%$ CRGC bean; 5.25 for the 3\% CAGC bean; 6.30 for the Indonesian coffee beans; and 6.37 for the $3 \%$ IWGC bean. Coffee beans coated with red ginseng extract or white ginseng extract evidenced higher $a$-values and $b$-values than the original coffee bean groups. However, those samples that were coated with American ginseng extract evidenced lower $a$ - and $b$-values than the original coffee bean groups. The lighter color of American ginseng extract relative to the other ginseng extracts appears to account for the lower chromaticity of the CAGC beans as compared to the original coffee beans. The $\mathrm{pH}$ test resulted in a lower $\mathrm{pH}$ for ginseng coffee beans than for the original coffee beans. Among the various samples, the $6 \%$ CRGC bean had the lowest $\mathrm{pH}$ value. These results are likely attributable to the fact that the manufacture of red ginseng coffee bean requires a greater amount of ginseng coating solution than does the manufacture of IWGC bean or CAGC bean. Furthermore, the lower $\mathrm{pH}$ value for the coated coffee beans, relative to that of the unprocessed coffee beans, may be attributable primarily to the acidic polysaccharides contained in the ginseng extracts. The $\mathrm{pH}$ value is believed to be associated with the sour taste of coffee, which explains why the Indonesian coffee beans evidence a lower $\mathrm{pH}$ value than the others, which are known for their sour taste. Our results, showing $\mathrm{pH}$ values in the range of 5.36 to 5.48 for the ginseng coffee beans, were clearly within a $\mathrm{pH}$ range of 5 to 6 , which is the $\mathrm{pH}$ value for Arabica coffee beans [12].

\section{Total sugar, acidic polysaccharides and phenolic concentrations}

The contents of the total sugar, acidic polysaccharides and phenolic compounds were measured, the results of which are shown in Table 4. With regard to total sugar content, the Columbian coffee beans contained $4.89 \%$ sugar; the $6 \%$ CRGC bean contained $6.07 \%$; and the $3 \%$ CAGC bean contained 5.23\%. Additionally, the 3\% 
Table 4. Contents of total sugar, acidic polysaccharide and phenolic compound of ginseng coffee beans (\%)

\begin{tabular}{lccc}
\hline & Total sugar & $\begin{array}{c}\text { Acidic } \\
\text { polysaccharide }\end{array}$ & $\begin{array}{c}\text { Phenolic } \\
\text { compound }\end{array}$ \\
\hline Colombia bean (control) & $4.89 \pm 0.34$ & $0.60 \pm 0.14$ & $4.14 \pm 0.03$ \\
CRGC bean (6\%) & $6.07 \pm 0.05$ & $0.87 \pm 0.03$ & $4.88 \pm 0.22$ \\
CAGC bean (3\%) & $5.23 \pm 0.37$ & $0.68 \pm 0.18$ & $4.00 \pm 0.02$ \\
Indonesia bean (control) & $5.22 \pm 0.84$ & $0.56 \pm 0.02$ & $4.10 \pm 0.07$ \\
IWGC bean (3\%) & $6.06 \pm 0.71$ & $0.98 \pm 0.15$ & $4.55 \pm 0.05$ \\
\hline Data are expressed as mean $\pm S D$. & \\
CRGC, red ginseng Colombian coffee; CAGC, American ginseng \\
Colombian coffee; IWGC, white ginseng Indonesian coffee.
\end{tabular}

IWGC bean contained $6.06 \%$ sugar, whereas the Indonesian coffee beans contained 5.22\% sugar. In terms of the acidic polysaccharide contents, the Columbian coffee beans and Indonesian coffee beans contained $0.56 \%$ to $0.60 \%$; the ginseng coffee beans contained $0.68 \%$ to $0.98 \%$ of acidic polysaccharides. In terms of the phenolic compound contents, the Columbian coffee beans and Indonesian coffee beans contained $4.10 \%$ to $4.14 \%$; the ginseng coffee beans contained $4.00 \%$ to $4.88 \%$. The total sugar, acidic polysaccharide, and phenolic compound contents were found to be higher in the ginseng coffee beans as compared to the original coffee beans, and were shown to be positively related to the concentration of ginseng extracts in the coating solutions, as was reported in a previous study [13].

\section{Ginsenoside content}

The results of the ginsenoside content analysis are shown in Table 5. With regard to the 12 ginsenoside contents, the $6 \%$ CRGC bean contained a smaller total ginsenoside content than the $3 \%$ IWGC bean. This result may be explained by a previous study result showing that white ginseng extract contains $10.64 \%$ saponin, whereas red ginseng extract contains 3.13\% saponin, i.e., the red ginseng extract had a saponin content 3.39 times as low as the white ginseng extract [14]. The ginsenoside $\mathrm{Rg}_{3}$ contents of the different ginseng extracts demonstrates an approximately threefold difference between the red ginseng coffee bean $(0.410 \mathrm{mg} / \mathrm{g})$ and the American ginseng coffee bean $(0.128 \mathrm{mg} / \mathrm{g})$.

\section{Caffeine content}

The caffeine contents of the different ginseng coffee beans were measured, as shown in Table 6. In the caffeine content analysis, the Columbian coffee bean was found to contain $15.30 \mathrm{mg} / \mathrm{g}$; the $6 \%$ CRGC bean contains $13.45 \mathrm{mg} / \mathrm{g}$; and the $3 \%$ CAGC bean contains
Table 5. Ginsenoside contents of ginseng coffee beans $(\mathrm{mg} / \mathrm{g})$

\begin{tabular}{lccc}
\hline & CRGC bean (6\%) & CAGC bean (3\%) & IWGC bean (3\%) \\
\hline $\mathrm{Rg}_{1}+\mathrm{Re}$ & 0.424 & 0.635 & 0.468 \\
$\mathrm{Rf}$ & 0.112 & 0.011 & 0.079 \\
$\mathrm{Rg}_{2}+\mathrm{Rh}_{1}$ & 0.225 & 0.104 & 0.150 \\
$\mathrm{Rb}_{1}$ & 1.049 & 0.921 & 0.920 \\
$\mathrm{Rc}$ & 0.765 & 0.906 & 0.796 \\
$\mathrm{Rb}_{2}$ & 0.409 & 0.230 & 0.422 \\
$\mathrm{Rb}_{3}$ & 0.064 & 0.219 & 0.067 \\
$\mathrm{Rd}$ & 0.282 & 0.502 & 0.318 \\
$\mathrm{Rg}_{3}(\mathrm{~S}, \mathrm{R})$ & 0.410 & 0.128 & 0.245 \\
$\mathrm{Rh}_{2}$ & 0.003 & 0.011 & 0.002 \\
$\mathrm{Total}^{2}$ & 3.743 & 3.667 & 3.467 \\
\hline $\mathrm{CRGC}$, red ginseng Colombian coffee; CAGC, American ginseng
\end{tabular}

Colombian coffee; IWGC, white ginseng Indonesian coffee.

Table 6. Caffeine contents of ginseng coffee beans $(\mathrm{mg} / \mathrm{g})$

\begin{tabular}{lc}
\hline & Caffeine \\
\hline Colombia bean (control) & $15.30 \pm 0.13$ \\
CRGC bean (6\%) & $13.45 \pm 0.20$ \\
CAGC bean (3\%) & $13.24 \pm 0.20$ \\
Indonesia bean (control) & $15.31 \pm 0.12$ \\
IWGC bean (3\%) & $14.40 \pm 0.21$ \\
\hline
\end{tabular}

Data are expressed as mean $\pm \mathrm{SD}$.

CRGC, red ginseng Colombian coffee; CAGC, American ginseng Colombian coffee; IWGC, white ginseng Indonesian coffee.

$13.24 \mathrm{mg} / \mathrm{g}$. Additionally, the 3\% IWGC bean was found to contain $14.40 \mathrm{mg} / \mathrm{g}$, which is lower than the caffeine content in the Indonesian coffee beans containing 15.31 $\mathrm{mg} / \mathrm{g}$. These results may have been induced by a slight reduction of the caffeine content in the coffee beans upon the initiation of the coating process.

\section{REFERENCES}

1. Nam KY. The comparative understanding between red ginseng and white ginsengs, processed ginsengs (Panax ginseng C. A. Meyer). J Ginseng Res 2005;29:1-18.

2. Lee JW, Do JH. Market trend of health functional food and the prospect of ginseng market. J Ginseng Res 2005;29:206-214.

3. Kim NY, Han MJ. Development of ginseng yogurt fermented by Bifidobacterium spp. Korean J Food Cookery Sci 2005;21:575-584.

4. Sung JH, Han MJ. Quality characteristics of Jeungpyun manufactured by ginseng Makgeolli. Korean J Food Cookery Sci 2008;24:837-848.

5. Yoon BS, Hwang SY, Chun DS, Kong SK, Kang KO. An 
investigation of the characteristics of sponge cake with ginseng powder. Korean J Food Nutr 2007;20:20-26.

6. Cho YY, Cho KY. Medical foods eating by color. Seoul: Gwangmungak, 2003.

7. Shin KE, Choi SK, Rha YA. Quality characteristics of Tarakjuk added with ginseng (Panax ginseng C. A. Meyer). Korean J Culinary Res 2009;15:86-98.

8. Seo HS, Kim SH, Han BY, Hwang IK. Quality characteristics of coffee-sulgi (rice cake) with different ratios of ingredients and commercial scheme. Korean J Soc Food Cookery Sci 2004;20:170-179.

9. Dubois M, Gilles KA, Hamilton JK, Rebers PA, Smith F. Colorimetric method for determination of sugars and related substances. Anal Chem 1956;28:350-356.

10. Do JH, Lee HO, Lee SK, Jang JK, Lee SD, Sung HS. Colorimetric determination of acidic polysaccharide from
Panax ginseng, its extraction condition and stability. Korean J Ginseng Sci 1993;17:139-144.

11. Singleton VL, Rossi JA Jr. Colorimetry of total phenolics with phosphomolybdic-phosphotungstic acid reagents. Am J Enol Vitic 1965;16:144-158.

12. Kim HK, Hwang SY, Yun SB, Chun DS, Gong SK, Kang GO. A study of characteristics of different coffee beans by roasting and extracting condition. Korean J Food Nutr 2007;20:14-19.

13. Kim KT, Lee YC, Cho CW, Rhee YK, Bae HM. Quality characteristics of ginseng coffee treated by coating of white ginseng extract. J Ginseng Res 2010;34:1-7.

14. Ko SG, Lee RC, Choi YE, Im BO, Sung JH, Yoon KR. Analysis of ginsenosides of white and red ginseng concentrates. Korean J Food Sci Technol 2003;35:536-539. 